\title{
THE INFLUENCE OF A HIGH-VOLTAGE DISCHARGE ON THE OIL BOTTOM SEDIMENTS FORMED AT THE OIL STORAGE FACILITIES OF THE ATASU-ALASHANKOU STATION
}

\author{
Satybaldin A.Zh. ${ }^{1}$, Zhakipbaeyev B.Y. ${ }^{2}$, Tusipkhan A. ${ }^{1}$,Baykenov M.I. ${ }^{1^{*}}$, Khalikova Z.S. ${ }^{1}$, \\ Alpyssova G.K. ${ }^{1}$ \\ ${ }^{1}$ E.A. Buketov Karaganda University, Karaganda, Kazakhstan, murzabek_b@mail.ru \\ 2Orda University, Chimkent, Kazakhstan
}

\begin{abstract}
From three to ten per cent of the total oil produced can ultimately not be used for further processing. When the oil is transported by oil pipelines and oil tankers and stored in reservoirs, oil bottom sediments are deposited on the bottom comprising particles of mineral (non-oil origin) and the heaviest hydrocarbons, mainly paraffin series, whose specific gravity is higher than the density of oil and water. For reliable operation of the tanks, it must be periodically cleaned from the accumulated sediment. The study novelty is the use of the electrohydraulic effect for the processing of oil bottom sediments and creation of a waste-free technology for the disposal of oil bottom sediments in field conditions. The optimal mode for electrohydraulic impact, ensuring the destruction of bottom deposits of oil in the oil storage tanks of the Atasu-Alashankou station, is determined.
\end{abstract}

Keywords: electrohydraulic phenomenon, catalyst, oil bottom sediment.

\section{Introduction}

When oil is transported by an oil pipeline and oil-loading transports and stored in tanks, an oil bottom sediment consisting of particles of mineral and the heaviest hydrocarbons, mainly of the paraffin series, whose specific gravity is higher than the density of oil and water, is deposited at the bottom. The methods used for cleaning and disposing of oil bottom sediments (OBS) accumulated in reservoirs are not effective, so the problem is not solved today. At the same time, there are many technical difficulties with high cost processes, there is no economic interest. A scientific approach to the processes of processing oil-containing waste is of paramount importance. The most appropriate is an integrated waste management, i.e. processing of oil bottom sediments with maximum consideration of properties and the use of all components, as a result of which oil sedimentsbecome raw materials, reagents or fillers in the production process or participate in the processing of other waste $[1,2]$.

Methods of disposal and cleaning of the tanks and the containers are divided into three types: manual, mechanical and mechanized cleaning method using detergents. In the manual cleaning method, the container is steamed after removing solid residues, washed with hot water $(30-50) \mathrm{C}^{\circ}$ from the fire barrel at a pressure of (0.2-0.3) MPa. Washing water with the remaining oil sludge is pumped out by a pump.The mechanized method of tank cleaning on tankers is widely used in our country and abroad. With a mechanized cleaning method, surface contamination is washed with hot or cold water supplied under pressure through special washing machines as hydro monitors. The mechanized cleaning method significantly reduces the cleaning time, reduces the downtime of the tank, reduces the volume of heavy operations, which are harmful to human health, and reduces the cost of the tank cleaning process.

The disadvantages of the mechanized method of tank cleaning include a large consumption of thermal energy for heating cold water, the need to pump contaminated water to treatment facilities, and, relatively, large losses of light fractions from oil aggregates. The chemical-mechanized method of cleaning tanks using detergent solutions improves the quality of cleaning, the intensity of the cleaning process, and is characterized by a low degree of manual labour. The main disadvantages of the method that limit the possibilities of its practical application are the need to use a special reagent and further cleaning of detergent solutions from oil sludge [3-5]. 
In recent years, interest in low-energy effects on substances in order to change their properties has remained consistently high. In order to change the molecular structures of the fraction and create more desirable products, special oil refining processes are used. Taking into account the individual characteristics of the substance and with the right choice of the type of impact, it is possible to rearrangeits structure in the right direction without noticeable external energy costs. We used the electrohydraulic effect as such effects that control the structure of the substance. The essence of the effect is as follows: electrodes are injected into the liquid (most often into water), to which a high pulse voltage is applied. At the same time, complex processes occur, covering a wide range of different physical effects [6-8]. The development of new technological solutions aimed at efficient utilization of oil bottom sediments of oil storage facilities and reservoirs is significant on a national scale and has great practical significance for the Republic of Kazakhstan. The got light-boiling fractions using the cavitation phenomenon under the electrohydraulic effect and the process of hydrogenation of the oil bottom sediment will be used not only in oil refining but also in coal chemistry and petro-chemistry.To conduct systematic laboratory studies on the effect of electrohydroimpulse action on the physico-chemical structure of hydrocarbon compounds and for the release of light and medium fractions from the oil bottom sediment, an experimental stand, designed for processing oil and petroleum products with short-pulse discharges, was assembled.Two measuring electrodes are installed inside the cell, one of them is fixed, and the second was fixed on a micrometer screw to adjust the distance between the electrodes. Figure 1 shows a general view of the processing cell by electrohydroimpulsive action of oil and petroleum products.

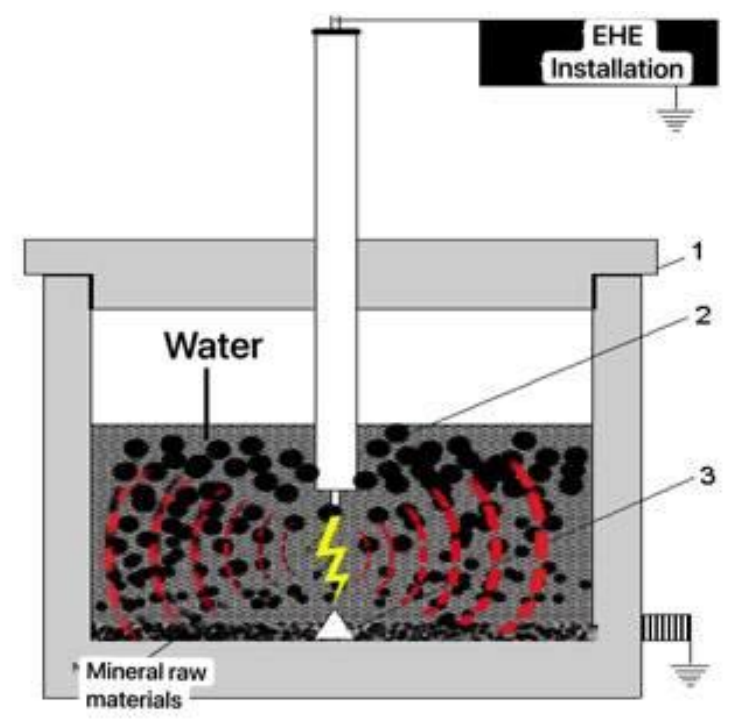

Fig.1.Working area for processing oil bottom sediment by electrohydroimpulse discharges: 1-cover; 2-positive electrode; 3-negative electrode

In the course of experimental studies, it was found that when a liquid(OBS) breaks through, a highpressure zone appears around the discharge channel, the diameter of which is proportional to the pulse power. High hydraulic pressures drop rapidly as they move away from the discharge, approximately proportional to the square of the distance from it.The liquid (OBS), having received acceleration from the discharge channel expanding at a higher speed, moves from it to all sides, forming a significant cavity in the place where the discharge was, called a cavitation cavity, and causing the first (main) hydraulic shock. Then the cavity closes at a high speed, creating a second cavitation hydraulic shock. At this point, the single cycle of the electrohydraulic effect ends, and it can be repeated an unlimited number of times, according to the specified frequency of repetition of discharges. When performing a sequential series of pulsed discharges in a liquid, each subsequent electrohydraulic shock can occur only after the cavitation cavity from the previous discharge has time to close, which determines the possible maximum frequency of discharges of the electrohydraulic installation [9-10].

The purpose of the research carried out in this work was to establish the possibility of increasing the efficiency of the thermocatalytic transformation of the oil bottom sediment due to the influence of the electrohydraulic effect. 


\section{Experimental technique}

Oil bottom sediments, which formed at the oil storage tanks of the Atasu-Alashankou station, were used as raw materials.Fly ash ferrospheres of TPP-3 (thermal power plant in Karaganda) were used as a catalyst. Microspheres were initially isolated from coal ashes, from which ferrospheres were then separated by magnetic separation. The chemical composition of ferrospheres is as follows, mass $\%: \mathrm{Fe}_{2} \mathrm{O}_{3}-83.4 ; \mathrm{CaO}-$ 7.6; $\mathrm{SiO}_{2}$ - 5.7; $\mathrm{Al}_{2} \mathrm{O}_{3}-3.2$; the rest is $\mathrm{MgO}, \mathrm{Na}_{2} \mathrm{O}, \mathrm{K}_{2} \mathrm{O}, \mathrm{TiO}_{2}, \mathrm{SO}_{3}$. After processing the oil bottom sediment of the Atasu-Alashankou oil storage tanks, the resulting product was divided into fractions: IBP-200 ${ }^{\circ} \mathrm{C}$ and $200-300^{\circ} \mathrm{C}$. The individual chemical composition of the light and middle fractions was determined using gas chromatography-mass spectrometry on an HP 5890/5972 MSD device from Agilent (USA).

\section{Results and discussion}

In the study of the effects of electrophysical characteristics ( $\mathrm{L}$ is the inter-electrode distance, $\mathrm{t}$ is the processing time, $\mathrm{C} \mathrm{mF}$ the capacitance of the capacitor bank, $\mathrm{U} \mathrm{kV}$ is the discharge voltage) of an electrohydraulic installation on the output of light and medium fractions fromOBS of the Atasu-Alashankou station. From the data obtained (Figure 1), it can be seen that the electrohydroimpulse effect affects the yield of light and medium fractions. With an increase in the processing time of the OBP of the Atasu-Alashankou station reservoirs from 2 to 8 minutes, an increase in the yield of light and medium fractions is observed from 18 to $74 \%$ (the interelectrode space of the processing cell is $\mathrm{L}=5-8 \mathrm{~mm}$ ). The data presented (Figures 2, 3) showed that with an increase in the discharge voltage from $12 \mathrm{kV}$ to $18 \mathrm{kV}$ and the capacity of the capacitor bank from $0.25 \mathrm{mF}$ to $1 \mathrm{mF}$, an increase in the yield of light and medium fractions from 18 to $74 \%$ is observed during the processing of the organic mass of the OBSformed at the Atasu-Alashankou oil storage facilities.

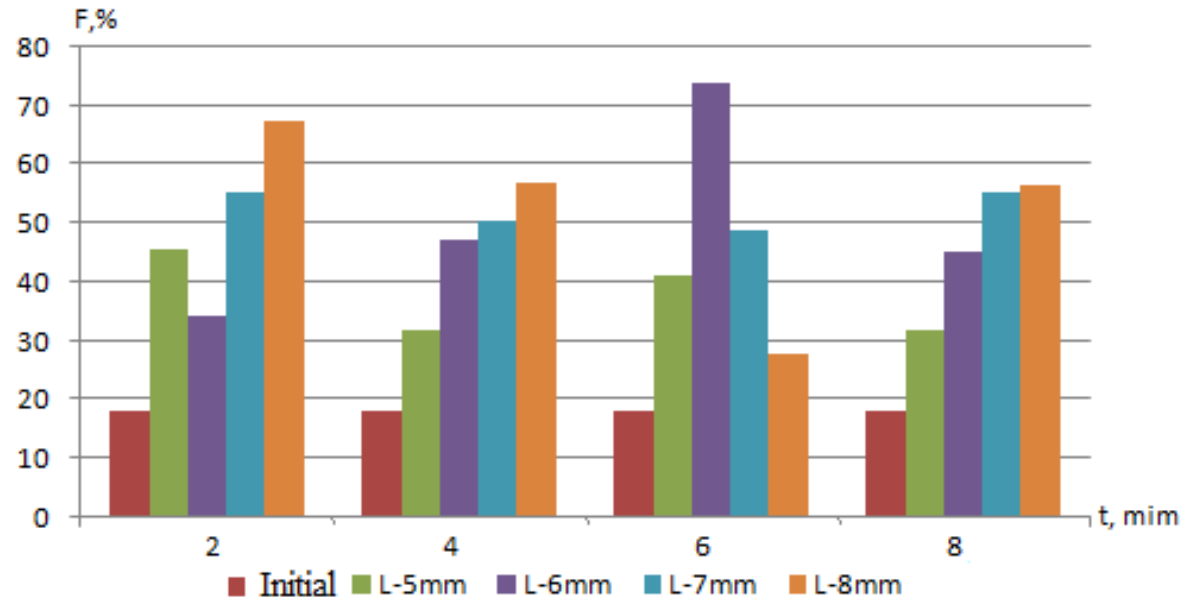

Fig.1.The effect of the time duration of electrohydroimpulse processing on the increase in the yield of light and medium fractions at the different interelectrode space

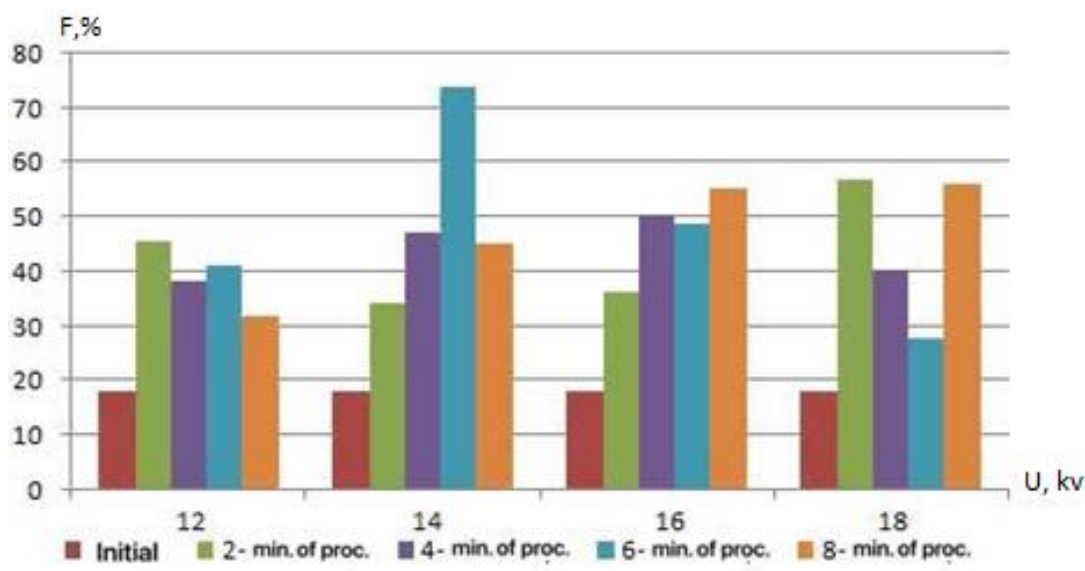

Fig.2.The effect of the discharge voltage on the increase in the yield of light and medium fractions from the OBS of the reservoirs of the Atasu-Alashankou station 


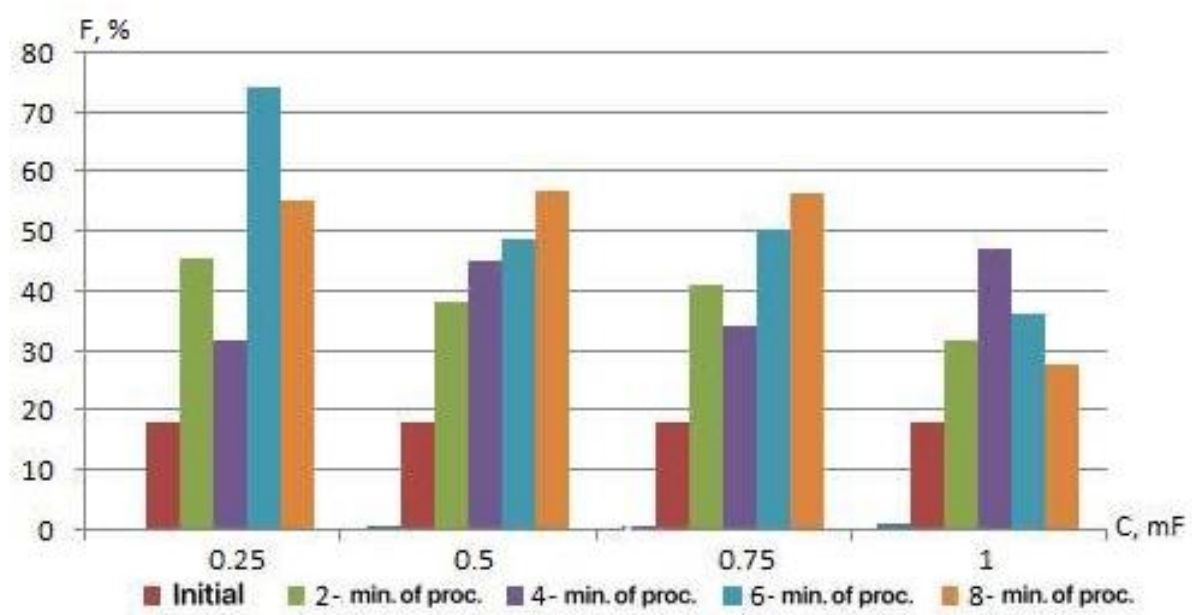

Fig.3.Influence of the capacity of the switching device on the increase in the yield of light and medium fractions from the OBS of the reservoirs of the Atasu-Alashankou station at the different interelectrode space

Fig.4 shows the effect of the amount of microsphere catalyst on the output of gasoline and diesel fuel. The amount of added catalyst (microspheres) ranged from 0.5 to $2.0 \%$ per feedstock. The given indicator of the influence of the amount of added catalyst to the deposits of the Atasu-Alashankou station showed that the amount of added catalyst above $1.0 \%$ leads to a decrease in the yield of target products from 74 to $47 \%$.It is important to note that an increase in the added catalyst by $1 \%$ increases the yield of solid residue (oilcoke) on the reactor surface and gas. These changes in the output of gas and oilcoke, gasoline and diesel fuel are associated with a change in the individual composition of the obtained fractions, possibly with the content of aromatic compounds of a mixed structure in the fractions.

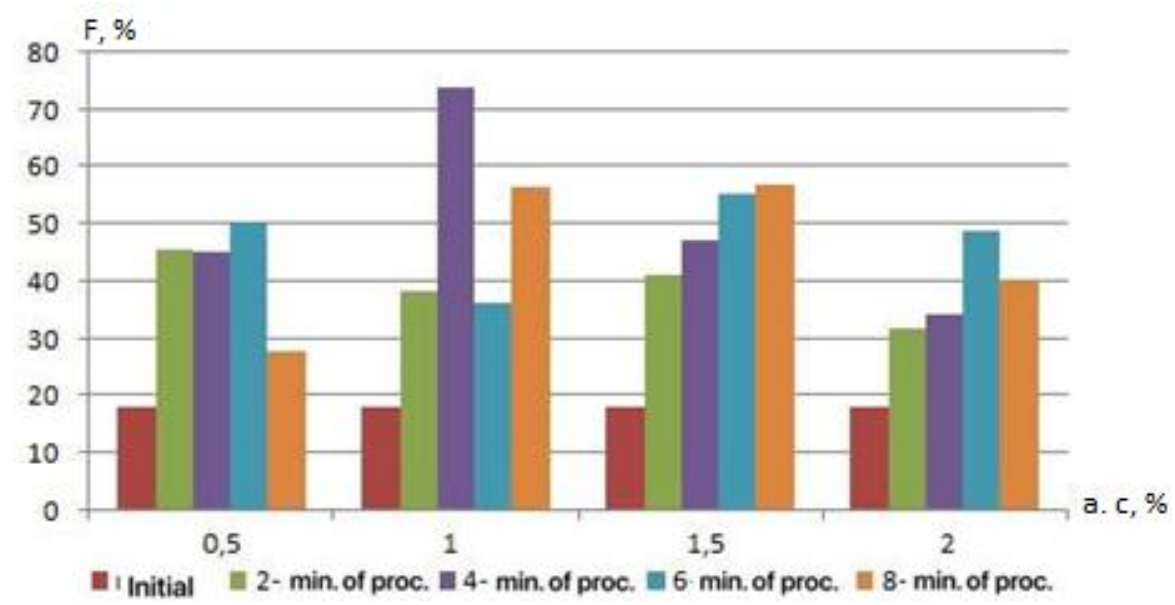

Fig.4. Influence of the amount of added catalyst on the yield of light and medium fractions from OBS of AtasuAlashankou

All factors ( $\mathrm{L}$ is the inter-electrode distance, $\mathrm{t}$ is the processing time, $\mathrm{C} \mathrm{mkF}$ the capacitance of the capacitor bank, $\mathrm{U} \mathrm{kV}$ is the discharge voltage) of an electrohydraulic installationaffecting the yield of the target products presented in Figures 1-4 indicate the predominance of electrohydraulic processes based on the reaction of polymerization addition and the formation of free radicals during the action. This is evidenced by an increase in the output of gasoline and diesel fractions, gas and oilcoke. A comparative analysis of the influence of various factors shows that an increase in the total yield of gasoline and diesel fractions is associated with an increase in the interelectrode space from 2 to $6 \mathrm{~mm}$.

\section{Conclusion}

Thus, test experiments have shown that it is possible in principle to increase the efficiency of the process of catalytic cracking of petroleum raw materials under the action of an electrohydraulic effect. The achieved effect is associated with a change in the fractional and individual hydrocarbon composition of 
OBSof the Atasu-Alashankou station during its activation and consists in increasing the yield of gasoline, diesel fuel and reducing the yield of coke during cracking. As a result of the study, the following optimal conditions for the destruction of oil bottom sediment using electrohydraulic processing were determined: the duration of processing of the OBS of the Atasu-Alashankou station is 6 minutes, the interelectrode distance is $6 \mathrm{~mm}$, the amount of added catalyst in the OBS is $1 \%$, the capacitor capacity is $0.25 \mathrm{mF}$, the applied voltage is $14 \mathrm{kV}$. The results during the processing of oil bottom sediments with a high content of mechanical impurities by electro hydro impulse discharges make it possible to get up to $60 \%$ of liquid hydrocarbons, which can be used (after refinement) as motor fuel.

\section{Acknowledgments}

The work was carried out within the framework of the grantAP09563282of the Ministry of Education and Science of the Republic of Kazakhstan.

\section{REFERENCES}

1 Kuvykin N. A., Bubnov A. G., Grinevich V. I. Hazardous industrial waste.Hazardous industrial waste. Study guide. 2004, 148 p. [in Russian].

2 Grosheva M.A. Innovation and investment support of oil-containing waste processing. Synopsis of the dissertation by $\mathrm{PhD}$ of Economical Sciences. 2006, 28 p. [in Russian].

3 Mansur A. Recovery and characterization of oil from waste crude oil tank bottom sludge from Azzawiya oil refinery in Libya. J. Adv. Chem. Eng., 2015, Vol.5, pp.1-11.

4 Shtin I.V. Technology of erosion of bottom sediments in reservoirs type of RVS. Pipeline transportation of oil. Appendix, 2001, No. 12, pp. 22 - 28. [in Russian].

5 Gimaletdinov G.M., Sattarova D.M. The methods for cleaning and preventing the accumulation of bottom sediments in reservoirs. Oil and gas business. 2006, pp. 1-12. [in Russian]

6 Satybaldin A.Zh., Sadenova K.K., Ospanova D.A. Quantum-chemical calculation of destruction of oil asphalten structure in the process of electrohydropulse influence. Eurasian Physical Technical Journal. 2011, Vol. 8, No. 2(16), pp. 25-28.

7 Satybaldin A.Zh. Electro hydro-impulse technology of processing of oil sludge and oilcontaining technogenic raw materials. Report on research work (final). 2017, No. 0115PK00430, 75 p. [in Russian].

8 Satybaldin A.Zh., Baikenov M.I., Aitpayeva Z.K., Karimova A.B., Rakhimzhanova N.Zh. Investigation of the influence of electrohydroimpulse technology on physical-chemical characteristics of oil sludges. Bulletin of the Karaganda University. Chemistry. 2017, No. 3, pp. 131-136. [in Russian].

9 Kussaiynov K.K., Satybaldin A.Zh., Sadenova K.K., Sagimbekova M.N. Electrohydropulse technology processing of oil slimes and oil-containing technogenic raw materials. Eurasian Physical Technical Journal. 2015, Vol.11, No.1 (23), pp. 65-69.

10 Baikenov M.I.,Satybaldin A.Zh., Aitpayeva Z.K., Karimova A.B. Determination of optimal electro-physical parameters of the process of degradation of Zhanaozen oil sludge with the help of electrohydraulic effect. Proceeding of the VI ${ }^{\text {th }}$ Intern. Scien. Conf." Theoretical and experimental chemistry", Karaganda, 2017, p. 112-113. [in Russian]. 